\title{
Barriers to Providing Quality Physical Education in Primary Schools in Ghana
}

\author{
Seidu Sofo ${ }^{1}$ and Eugene F. Asola ${ }^{2}$ \\ ${ }^{I}$ Professor, Department of Health, Human Performance \& Recreation, Southeast Missouri State University, \\ USA \\ ${ }^{2}$ Assistant Professor, Department of Kinesiology \& Physical Education, Valdosta State University, USA
}

\begin{abstract}
The goal of physical education (PE) is to develop physically literate individuals to pursue a lifetime of healthful physical activity. Schools in Ghana, like other sub-Saharan African countries, do not implement their PE programs in accordance to policy. Thus, it is important to identify those factors that prevent schools from delivering quality PE. Therefore, the purpose of the present study was to examine what primary school teachers in Ghana perceived as barriers to teaching PE. Participants were 296 primary school teachers purposively selected from four regions of Ghana. An 11-item 5-point Likert-type questionnaire served as the data source. The study utilized descriptive and inferential statistical tools for data analysis. Results revealed four major barriers to teaching PE: lack of resources such as teacher's guide, lack of time, lack of support from other teachers and lack of adequate training. Independent t-Test showed that gender significantly influenced teachers' perception of barriers to teaching PE, while school type did not. One-Way ANOVA showed that professional qualification influenced the teachers' perceptions about the importance of PE.
\end{abstract}

Keywords: Barriers, Ghana, physical education, teachers

\section{Introduction}

The goal of physical education (PE), according to [1], is to develop physically literate individuals to pursue a lifetime of healthful physical activity by helping them acquire the requisite knowledge and skills. Sports and PE contexts provide children with experiences that allow them to cope with challenges they face across the lifespan [2]. Research indicates that physical activity benefits health and contributes to academic performance [3], as a result of better cognitive functioning [4]. Researchers, for example [5], noted that physical activity in early life optimizes brain functions that involve memory and influences individual's learning capability throughout the life span. Sedentary behaviors are associated with chronic but preventable diseases such as obesity, coronary diseases, and diabetes [6].

Physical activity also improves self-esteem and reduces anxiety and stress among individuals [7]. Childhood obesity is one cause of anxiety among school children. Obese children are systematically discriminated against; as a result, they tend to develop a negative self-image that appears to persist into adulthood [8]. The fight against childhood obesity should be a concern for schools, since there is high probability for obese children to continue to be obese as adults [9]. The [10] recommends at least 60 minutes of moderate to vigorous physical activity a day for young children. Physical activity for children includes "play, games, sports, transportation, recreation, physical education, or planned exercise, in the context of family, school and community activities" [10:20]. School PE can play a vital role in achieving the recommended amounts of physical activity. However, in a global survey of the situation of PE in schools, [11] observed that the sports dominated nature of PE in many countries runs counter to achieving this goal. Furthermore, research indicates that most children do not accrue sufficient amounts of moderate to vigorous physical activity $[12,13]$. Major goals of primary school PE in Ghana are to help students to develop their personal health, moral and social capabilities, and self-confidence [14]. The Ministry of Education Science and Sports (MOESS, 2007) noted the role PE can play towards academic work and the improvement of the general health of the community [14]. Some scholars and researchers have lamented that the early years are important for developing fundamental motor skills that, in turn, contribute to the optimal development of physical capacities, yet only $60 \%$ of African countries actually implemented their PE programs in accordance with policy [11]. In Ghana, for example, successive governments have not demonstrated total commitment to PE as a school subject [15]. Major barriers to providing PE in schools are classified as institutional or teacher-related [16]. They defined institutional barriers as those factors that are beyond teachers' control, while teacher-related barriers result from teachers' behaviors. In addition, student-related barriers have been shown to inhibit the delivery of quality PE [17 18]. Examples of institutional barriers include lack of time, marginalization of the subject, timetabling, and lack of resources. Lack of training and confidence are some teacher-related barriers to teaching PE. Lack of student interest and motivation are student-related factors that often impede the teaching of PE [17, 19]. In Ghana, non-specialist classroom teachers are responsible for teaching primary PE. Some barriers to teaching 
primary physical education in Ghana include: lack of qualified personnel, lack of time, marginalization of the subject, and inadequate facilities/equipment [15]. More research is needed to unearth other reasons that might prevent Ghanaian primary school teachers from providing quality PE to their students.

\section{Purposes of the Study}

The purpose of the study was to examine what primary school teachers in Ghana perceived as barriers to teaching PE. The PE program has the opportunity to make the most impact on students' physical activity levels, since it is the only component of the school program that offers physical activity experiences [20]. Thus, it is important to identify those factors that serve as barriers to teaching PE, only then can teachers and educational administrators formulate strategies to mitigate them.

\section{Research Questions}

The study posed three research questions in an attempt to identify the barriers to teaching PE in Ghanaian primary schools:

1. What do primary school teachers perceive to be the barriers to teaching physical education in Ghana?

2. Do gender and school type influence primary school teachers' perceived barriers to teaching physical education in Ghana?

3. Does professional qualification influence what Ghanaian primary school teachers perceive as barriers to teaching physical education?

\section{Participants}

Participants included a purposive sample of 296 primary (P1-P6) school teachers from four regions of Ghana: Greater-Accra, Northern, Upper East, and Upper West regions. The sample consisted of $49.7 \%$ male and $50.3 \%$ female, with teaching experience ranging from one to 33 years $(\mathrm{M}=8.7 ; \mathrm{SD}=7.5)$.

\section{Instrument}

\section{Method}

The current study utilized a questionnaire that was adapted from [21] study on the barriers to teaching physical activity in Ghanaian kindergarten classrooms. The questionnaire used by [21] was based on extant literature on barriers to teaching PE, for example [17]. The items were rephrased to pertain to primary physical education. The questionnaire was an 11-item 5-point Likert scale. The questionnaire consisted of 11 items (perceived barriers) in addition to biographical information including gender, teaching experience, class taught, and professional qualification. Participants indicated the extent to which they agreed or disagreed to each of the 11 statements by checking the appropriate box for strongly agree (5), agree (4), neutral (3), disagree (2) or strongly disagree (1). Thus, a high rating (5 or 4 ) meant that respondents viewed the questionnaire item to be a major barrier, while a low rating ( 2 or 1 ) for an item meant the item was not perceived as a barrier to teaching movement and physical activity. The questionnaire had a Cronbach's Alpha of .738.

\section{Data Analysis}

Data were analyzed using descriptive and inferential statistics. First, frequency counts and percentages of teachers' responses for each item were computed. Second, using the overall mean scores, Independent t-Test analyses were conducted for gender and school type. Third, One-Way Analysis of Variance (ANOVA) tests, with Bonferroni Post-Hoc follow-up, were conducted for professional qualification, using the overall mean scores and the mean score for each questionnaire item. The SPSS Version 23.0 software [22] was used for all analyses.

\section{Perceived Barriers}

\section{Results}

The first research question examined what the primary school teachers perceived to be the barriers to teaching physical education. The teachers in the present study identified lack of resources, lack of enough class time, lack of support from other teachers, and lack of adequate training as the major barriers to teaching physical education. Table 1 shows that $63.2 \%$ of the teachers strongly agreed or agreed that lack of resources such as teacher's guide served as a major barrier to teaching physical education to their students, followed by lack of adequate time for the subject (59.7\%). Similarly, $49.5 \%$ and $48.4 \%$ believed lack of support from other teachers and lack of adequate training respectively hindered their ability to teach physical education. On a positive note, most of the teachers $(88.7 \%)$ in the present study strongly disagreed or disagreed with the statement that physical education is not an important subject. Also, they did not agree that students were not interested in physical education (84.2\%). In addition, they did not agree that physical education will make them sweaty (82.2) $\%$ and they did not use time for physical education to teach other subjects $(82.2 \%)$. 


\section{Gender, school type and perceived barriers}

The second research question sought to determine if gender and school type influenced the teachers' perception of barriers to teaching PE. Data in Table 2 indicated that the overall mean score difference for gender was significant, while that of school type was not. Male teachers $(\mathrm{M}=2.70)$ were more likely than their female counterparts $(\mathrm{M}=2.51)$ to perceive the statements on the questionnaire as major barriers to teaching PE.

\section{Professional Qualification and Perceived Barriers}

The third research question examined the influence of professional qualification on what teachers perceived as barriers to teaching PE. Table 3 presents One-Way ANOVA data for overall mean score and the mean score for each item. Only the mean differences for the item "PE is not an important subject" was significant. The multiple comparison showed a significant mean difference for teachers with a bachelor's degree (3.15) and those with a post-secondary certificate "A" (2.92). That is, teachers with a bachelor's degree, more likely than those with a post-secondary certificate A viewed PE not to be an important subject. Those for the other 10 items and the overall mean score for the entire questionnaire were not significant.

\section{Tables}

Table 1: Frequency counts and percentages for perceived barriers $(n=296)$

\begin{tabular}{|l|c|c|c|c|c|c|}
\hline Barrier & \multicolumn{2}{|c|}{ Strongly Agree/Agree } & \multicolumn{2}{c|}{ Neutral } & \multicolumn{2}{c|}{ Disagree/Strongly Disagree } \\
\hline & $\mathrm{f}$ & $\%$ & $\mathrm{f}$ & $\%$ & $\mathrm{f}$ & $\%$ \\
\hline 1. Not enough class time for PE & 175 & 59.7 & 44 & 15.0 & 74 & 25.3 \\
\hline 2. Lack of adequate training & 142 & 48.4 & 32 & 10.9 & 119 & 40.6 \\
\hline 3. Students are not interested & 20 & 6.9 & 26 & 8.9 & 246 & 84.2 \\
\hline 4. PE is not important & 18 & 6.2 & 15 & 5.1 & 260 & 88.7 \\
\hline 5. Lack required physical fitness & 45 & 15.4 & 29 & 9.9 & 219 & 74.7 \\
\hline 6. Don't have enough resources & 185 & 63.2 & 42 & 14.3 & 66 & 22.6 \\
\hline 7. PE specialist's responsibility & 67 & 22.9 & 26 & 8.9 & 200 & 68.3 \\
\hline 8. No support from other teachers & 145 & 49.5 & 46 & 15.7 & 102 & 34.9 \\
\hline 9. No support from headteacher & 92 & 31.5 & 67 & 22.9 & 266 & 45.6 \\
\hline 10. I will be sweaty and smelly & 33 & 11.2 & 19 & 6.5 & 241 & 82.2 \\
\hline 11. Time used for other subjects & 33 & 11.2 & 19 & 6.5 & 241 & 82.2 \\
\hline
\end{tabular}

Table 2: Independent t-Test Analyses for gender, school type, and perceived barrier $(\mathrm{n}=296)$

\begin{tabular}{|l|c|c|c|c|}
\hline Category & \multicolumn{2}{|c|}{ Overall Mean Score } & \multicolumn{2}{c|}{ t-value } \\
\hline & $\mathrm{M}$ & $\mathrm{SD}$ & $\mathrm{t}$ & $\mathrm{P}$ \\
\hline Gender & & & & \\
\hline Male & 2.70 & .63 & 2.46 & $.015^{*}$ \\
\hline Female & 2.51 & .67 & & \\
\hline School Type & & & & \\
\hline Public & 2.61 & .67 & .21 & .830 \\
\hline Private & 2.59 & .55 & & \\
\hline
\end{tabular}

$$
* \mathrm{p}<.05
$$

Table 3: One-Way ANOVA for professional qualification and perceived barriers for each questionnaire item

\begin{tabular}{|c|c|c|c|c|c|c|c|c|c|c|}
\hline \multirow[t]{2}{*}{ Category } & \multicolumn{2}{|c|}{$\begin{array}{l}\text { Untrained } \\
(\mathrm{n}=36)\end{array}$} & \multicolumn{2}{|c|}{$\begin{array}{l}\text { Post-Sec Cert } \\
\text { "A" }(n=30)\end{array}$} & \multicolumn{2}{|c|}{$\begin{array}{l}\text { Diploma } \\
(\mathrm{n}=133)\end{array}$} & \multicolumn{2}{|c|}{$\begin{array}{l}\text { Bachelor's } \\
\text { degree }(n=90)\end{array}$} & \multicolumn{2}{|c|}{ F-value } \\
\hline & $\mathrm{M}$ & SD & $\mathrm{M}$ & SD & M & SD & $\mathrm{M}$ & SD & $\mathrm{F}$ & $\mathbf{P}$ \\
\hline 1. Not enough class time for PE & 3.53 & 1.34 & 3.63 & 1.43 & 3.56 & 1.32 & 3.52 & 1.28 & .06 & .982 \\
\hline 2. Lack of adequate training & 2.92 & 1.36 & 3.57 & 1.43 & 3.11 & 1.45 & 3.15 & 1.47 & 1.19 & 313 \\
\hline 3. Students are not interested & 1.46 & .89 & 1.77 & .90 & 1.65 & 1.05 & 1.96 & 1.08 & 2.59 & .053 \\
\hline 4. PE is not important & 1.33 & .76 & 1.30 & 47 & 1.54 & 96 & 1.77 & 1.16 & 2.76 & $.043^{*}$ \\
\hline 5. Lack required physical fitness & 1.86 & 1.28 & 2.23 & 1.19 & 1.21 & .12 & 1.22 & .13 & .94 & .424 \\
\hline 6. Don't have enough resources & 3.31 & 1.56 & 3.37 & 1.45 & 3.62 & 1.45 & 3.90 & 1.20 & 2.13 & 097 \\
\hline 7. PE specialist's responsibility & 2.19 & 1.31 & 2.10 & 1.37 & 2.14 & 1.34 & 2.60 & 1.47 & 2.31 & .076 \\
\hline 8. No support from other teachers & 3.03 & 1.32 & 3.17 & 1.37 & 3.22 & 1.39 & 3.29 & 1.42 & .31 & 813 \\
\hline 9. No support from headteacher & 2.67 & 1.41 & 3.37 & 1.30 & 2.70 & 1.34 & 2.78 & 1.30 & 2.16 & .093 \\
\hline 10. I will be sweaty and smelly. & 1.44 & .94 & 1.53 & .97 & 1.72 & 1.11 & 1.83 & 1.29 & 1.24 & 293 \\
\hline 11. Time used for other subjects & 2.61 & 1.36 & 2.93 & 1.62 & 3.33 & 1.48 & 3.26 & 1.54 & 2.53 & 057 \\
\hline Overall Mean Score & 2.19 & 1.31 & 2.10 & 1.37 & 2.13 & 1.34 & 2.60 & 1.47 & 2.31 & .076 \\
\hline
\end{tabular}
$* \mathrm{p}<.05$

\section{Discussion and Conclusions}

The current study surveyed primary school teachers in Ghana about what they perceived as barriers to teaching PE. Four major findings from the study are worth discussing. First, the perceived barrier identified by most of the teachers was lack of resources such as teacher's guide/manual. This finding is consistent with previous studies on barriers to teaching PE in Africa [11] and Ghana [21]. A similar percentage (62\%) of kindergarten teachers in Ghana also identified lack of resources as a major barrier to teaching movement and physical activity [21]. Primary school teachers are non-specialists - they need resources such as teacher's 
guides and manuals on how to deliver quality PE to their students. These resources, in addition to regular inservice training, would help classroom teachers develop confidence, effective instructional strategies and practices for teaching PE. Second, male teachers were more likely than female teachers to perceive the statements on the questionnaire as major barriers to teaching PE. This is inconsistent with a previous study [21] that found no significant gender differences in kindergarten teachers' perceptions of barriers to teaching movement and physical activity. The sport-oriented nature of the primary PE [11] curriculum may explain the tendency for male teachers to focus on sports, rather than instructional PE. Consequently, they would more likely perceive issues relating to the regular PE class as barriers. Third, the perceived barriers to teaching PE between teachers in public and those in private primary schools were similar. With opportunities of better logistics and personnel from government, authors of the current study expected teachers in private schools to encounter more barriers than their peers in public schools. During the 2013/2014 academic year, for example, a little over seven percent of teachers in private schools were trained, while public schools had over $70 \%$ trained teachers [23]. Finally, professional qualification influenced teachers' views of the importance of PE as a school subject. This finding is consistent with the research that PE is a marginalized subject $[11,15]$. Participants with a Bachelor's degree were more likely than those with a Post-Secondary Certificate "A" to perceive more barriers in teaching PE.

The present study replicated the use of a forced-choice survey instrument [21], and therefore did not examine why and how those perceived barriers impacted the teaching of PE. The use of open-ended questionnaires or interviews would allow future researchers to have better insight into why and how the perceived barriers influence the quality of PE in Ghanaian primary schools. The use of observation as a data collection tool would also provide information on the quality of PE in the primary classrooms [21]. It would also allow future research determine first-hand, the extent to which each barrier impacts student outcomes in PE.

\section{References}

[1]. SHAPE America \& Human Kinetics (2014). National standards \&grade-level outcomes for K-12 physical education. Retrieved May 31, 2016 from http://www.shapeamerica.org/standards/upload/National-Standards-Flyer-rev.pdf

[2]. American College of Sport Medicine (2016). Physical activity, fitness, cognitive function, and academic achievement in children: A systematic review. Medicine \& Science in Sports \& Exercise, 48(1), 1197-122. DOI: 10.1249/MSS.0000000000000901

[3]. Trudeau, F. \& Shephard, R. (2008). Physical education, school physical activity, school sports and academic performance. International Journal of Behavioral Nutrition and Physical Activity, 5(10), 1-12.

[4]. Sibley, B. A, \& Etnier J. L. (2003). The relationship between physical activity and cognition in children: A meta-analysis. Pediatric Exercise Science 15, 243-256.

[5]. Kempermann, G. (2008). The neurogenic reserve hypothesis: What is adult hippocampal neurogenesis good for? Trends in Neuroscience, 31(4), 163-169.

[6]. Martyniuk, O. J.M., \& Tucker, P. (2014). An exploration of early childhood education students' knowledge and preparation to facilitate physical activity for preschoolers: A cross-sectional study. BMC Public Health 14, 727. Retrieved from June 6, 2016 http://www.biomedcentral.com/1471-2458/14/727

[7]. Chalkley, A., Milton, K., \& Foster, C. (2015). Change4Life evidence review. Public Health England publications gateway number: 2015154.

[8]. Dietz, W.H. (1998). Health consequences of obesity in youth: Childhood predictors of adult disease. Pediatrics 101(3 Pt 2), 518525 .

[9]. Serdula, M. K., Ivery, D., Coates, R. J., Freedman, D. S., Williamson, D. F., \& Byers, T. (1993). Do obese children become obese adults? A review of the literature. Preventive Medicine, 22, 167-177.

[10]. World Health Organization (2015). Global recommendations on physical activity for health. Retrieved March 19, 2016 from http://apps.who.int/iris/bitstream/10665/44399/1/9789241599979_eng.pdf

[11]. Hardman, K. (2008). Physical education in schools: A global perspective. Kinesiology, 40(1), 5-28.

[12]. Basterfield L, Jones AR, Parkinson KN, Reilly J, Pearce MS, Reilly JJ, et al. (2014). Physical activity, diet and BMI in children aged 6-8 years: a cross-sectional analysis. BMJ Open. 4(6), e005001. doi: 10.1136/bmjopen-2014-005001.

[13]. Janz, K. F., Letuchy, E. M, Eichenberger, G. J. M., Burns, T. L., Torner, J. C., Willing, M. C., et al. (2010). Early physical activity provides sustained bone health benefits later in childhood. Medicine \& Science in Sports \& Exercise. 42(6), 1072-1078.

[14]. Ministry of Education Science \& Sports (2007). Teaching syllabus for physical education (Primary 1-6). Accra: MOESS.

[15]. Ammah, J.O.A.A., \& Kwaw, N.P. (2005). Physical Education in Ghana. In U. Puhse \& M. Gerber (Eds.). International Comparison of Physical Education. Concept - Problems - Prospects. Aachen, Meyer \& Meyer Verlag. pp. 311-327.

[16]. Morgan, P. J. \& Hansen, V. (2008). Classroom teachers' perceptions of the impact of barriers to teaching physical education on the quality of physical education programs. Research Quarterly for Exercise and Sport, 79(4), 506-516.

[17]. Jenkinson, K. A., \& Benson, A. C. (2010). Barriers to providing physical education and physical activity in Victorian State secondary schools. Australian Journal of Teacher Education, 35(8).

[18]. Mowling, C. M., Brock, S. J., Eiler, K. K. \& Rudisill, M. E. (2004). Student motivation in physical education. Journal of Physical Education, Recreation \& Dance, 75(6), 40-51.

[19]. Kinnunen, D. A., \& Lewis, D. K. (2013). A case study of preservice physical education teachers' attitudes toward and perceived barriers to quality physical education. Journal of Education and Practice, 4(8), 123-133.

[20]. National Association for Sport and Physical Education (2004). Moving into the future: National standards for physical education (2nd ed). Reston, VA: NASPE

[21]. Sofo, S., \& Asola, E. F. (2015). Perceived barriers to teaching movement and physical activity to kindergarteners in Ghana. Journal of Education and Practice, 6(36), 134-140.

[22]. IBM Corp. Released 2014. IBM SPSS Statistics for Windows, Version 23.0. Armonk, NY: IBM Corp.

[23]. Ministry of Education (2014). Report on basic statistics and planning parameters for basic education in Ghana 2013/2014. Accra: Ministry of Education 